\title{
Ocorrência de opacidades corneanas (Florida spots) em gatos atendidos no Hospital de Clínicas Veterinárias da UFRGS
}

\author{
Occurrence of corneal opacities (Florida Spots) in cats referred to the \\ Veterinary Medical Teaching Hospital/UFRGS \\ Mauro Luís da Silva Machado ${ }^{1}$ Nina Isabel Baptista² \& Irene Breitsameter ${ }^{2}$
}

\begin{abstract}
RESUMO
Florida Spots são opacidades corneanas que acometem cães e gatos, observada primeiramente em gatos no Sul da Florida-EUA. A etiologia ainda é desconhecida e origens micótica, bacteriana (micobactéria) ou por efeito físico da incidência de luz ultravioleta já foram sugeridas, porém, não comprovadas. O objetivo deste trabalho foi conhecer a ocorrência de Florida Spots em gatos atendidos na clínica geral do Hospital de Clínicas Veterinárias da UFRGS (HCV), Porto Alegre - RS e sua relação com sexo, idade, raça e ambiente (outros contatantes felinos). Escolheu-se aleatoriamente 100 gatos conduzidos à consulta no hospital por motivos diversos no ano de 2001. Observou-se Florida Spots em $32 \%$ dos animais, dos quais $43,75 \%$ eram afetados unilateralmente ( $57 \%$ o olho esquerdo e $43 \%$ o olho direito). Foi significativa a diferença estatística em relação à raça (SRD foram os mais afetados $(\mathrm{p}<0,05)$ e também significativo em relação aos animais que tiveram contato com outros gatos $(\mathrm{p}<0,05$ ). $\mathrm{O}$ fato de animais $\mathrm{SRD}$ (que habitualmente são criados de forma mais livre, o que permite o contato com outros gatos) e animais que, independente da raça, tiveram contato com outros serem os mais afetados, induz-nos a pensar na possibilidade de haver um agente etiológico transmissível envolvido nesta afeção, e não fatores físicos ambientais.
\end{abstract}

Descritores: opacidades corneanas (Florida Spots), gatos.

\begin{abstract}
Florida Spots is a type of corneal opacity of dogs and cats that was primarily described in cats in South Florida, USA. Although the etiology of this disorder remains unknown, microorganisms (fungi and bacteria) and preconditioning by environmental physical stimuli such as ultraviolet light have been suggested, but yet to be proved, as causal factors of this pathology. The aim of this study was to describe the occurrence of Florida Spots in cats referred to the Veterinary Medical Teaching Hospital at UFRGS, Porto Alegre, RS and its relationship with sex, age, breed and environment (contact with others cats). One hundred randomly chosen cats admitted to the hospital during the year of 2001 were examined for this study. Symptoms for Florida Spots were detected in $32 \%$ of the cats, from which $44 \%$ were affected unilaterally ( $43 \%$ and $57 \%$ on the on the left and right eyes, respectively). Breed and environment had a significant effect on the prevalence of the condition $(\mathrm{P}<0.005)$, with crossed cats and animals normally raised outdoors, which allows direct contact with other cats, being the most affected animals. Such breed and environmental effects suggest the existence of a primary microorganism involvement in the appearance of this pathological condition.
\end{abstract}

Key words: corneal opacities (Florida Spots), cats.

Serviço de Oftalmologia do Hospital de Clínicas Veterinárias (HCV) da UFRGS, Porto Alegre,RS - Brasil. ${ }^{2}$ Clínica Médica de Pequenos Animais do HCV - UFRGS. CORRESPONDÊNCIA: M.L.S. Machado [mauro.vet-ufrgs@ bol.com.br ; FAX + 55 3316 6112]. 


\section{INTRODUÇÃO}

Denomina-se "Florida Spots" uma anomalia corneana que acomete cães e gatos, observada primeiramente em gatos no Sul do Florida, USA. Caracteriza-se por opacidades visíveis macroscopicamente, únicas ou multifocais, radialmente simétricas, com a região central mais densa, podendo se apresentar uni ou bilateralmente, principalmente no estroma da córnea. Diversos estudos sugeriram que as alterações não estão relacionadas com um agente infeccioso, mas resultantes de um estímulo físico em animais suscetíveis, como a luz ultravioleta [3].

Os olhos não apresentam sinais de inflamação ou desconforto e não respondem ao tratamento com antifúngicos ou corticosteróides. A visão também não é afetada significativamente. Em estudos de córneas afetadas, não foi isolado nenhum microorganismo patogênico. [4]

Um estudo clínico em dez cães e sete gatos reafirma a possibilidade da doença estar relacionada a uma micobactéria e que tratamentos com corticosteróides e antifúngicos foram ineficazes [1].

O objetivo do trabalho foi avaliar a ocorrência de opacidades corneanas (Florida Spots) em gatos atendidos na clínica geral do Hospital de Clínicas Veterinárias da UFRGS, Porto Alegre - RS e observar se essa afecção está relacionada com o sexo, idade, raça e ambiente social (contato com outros felinos ou não).

\section{MATERIAIS E MÉTODOS}

Foram escolhidos aleatoriamente 100 gatos conduzidos à consulta no referido hospital, por motivos diversos, no ano de 2001. Os felinos foram avaliados oftalmologicamente em busca de opacidades corneanas (Florida Spots). Anotaram-se os dados de sexo, idade, raça, e informações sobre o ambiente em que vivem, com ênfase na possibilidade de contato com outros felinos. Esses dados foram cotejados com os achados oftalmológicos e avaliados por Teste de Associação, utilizando-se o Qui-Quadrado. Valores de $\mathrm{p}<0,05$ foram considerados significativos. A análise estatística foi efetuada através do software The Student Edition of Statistx, version 4.0.

Dentre os 100 animais estudados, $80 \%$ eram animais sem raça definida (SRD) e $20 \%$ gatos com raça definida (60 \% siamês e $40 \%$ Persa); $55 \%$ eram fêmeas, $74 \%$ tinham mais de um ano de idade e $87 \%$ tinham ou tiveram com outros gatos.

\section{RESULTADOS}

Foram observados "Florida Spots" em $32 \%$ dos animais, dos quais $56,25 \%$ foram afetados bilateralmente e os demais $43,75 \%$ afetados unilateralmente, $57 \%$ acometia o olho esquerdo e $43 \%$ o olho direito.

Não houve diferença estatística significativa entre os animais afetados em relação ao sexo e a idade, entretanto foi significativa a diferença em relação à raça, sendo os SRD os mais afetados $(\mathrm{p}<0,05)$ e também significativo em relação aos animais com contato com outros gatos $(\mathrm{p}<0,05)$.

\section{DISCUSSÃO}

Este levantamento, embora realizado com uma população específica - gatos que foram levados ao Hospital Veterinário por motivos diversos - demonstra o alto índice de animais afetados na região de Porto Alegre. $\mathrm{O}$ fato de animais SRD (que habitualmente são criados de forma mais livre, o que permite o contato com outros gatos) e animais que, independente da raça, tiveram contato com outros gatos serem os mais afetados, induz-nos a pensar na possibilidade de haver um agente etiológico transmissível envolvido nessa afeção, e não fatores físicos ambientais. Atualmente o organismo suspeito é uma micobactéria devido as suas características e a tendência a corar-se em cortes histológicos pelo corante Ziehl-Neelsen carbolfucsina. [2]

As lesões variam em tamanho de 1 a $8 \mathrm{~mm}$ de diâmetro e são tipicamente múltiplas. Não se observam outras anormalidades e a condição é não-progressiva.

\section{CONCLUSÃO}

Apesar da doença aparentemente não causar déficit visual e desconforto aos animais, a sua etiologia é ainda obscura, devendo, portanto, ser continuamente investigada, pois sendo as lesões visíveis macroscopicamente, causam grande apreensão nos proprietários. 


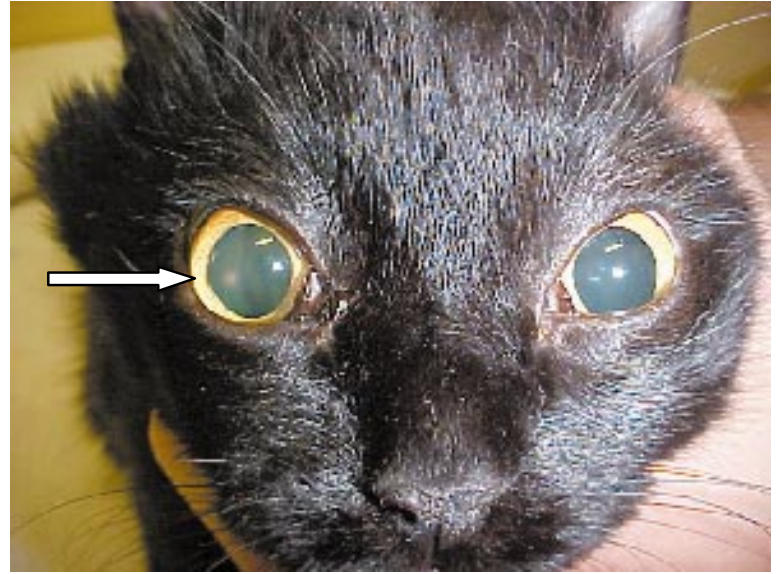

Figura 1. Felino, SRD, macho, 3 anos. Florida Spot unilateral com apresentação única no olho direito.

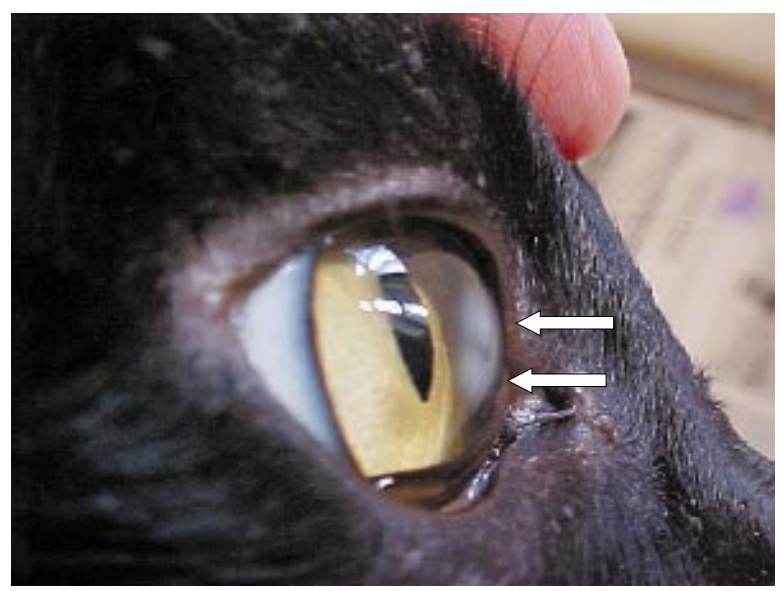

Figura 3. Felino, SRD, fêmea. Florida spot unilateral com apresentação múltipla no olho direito.

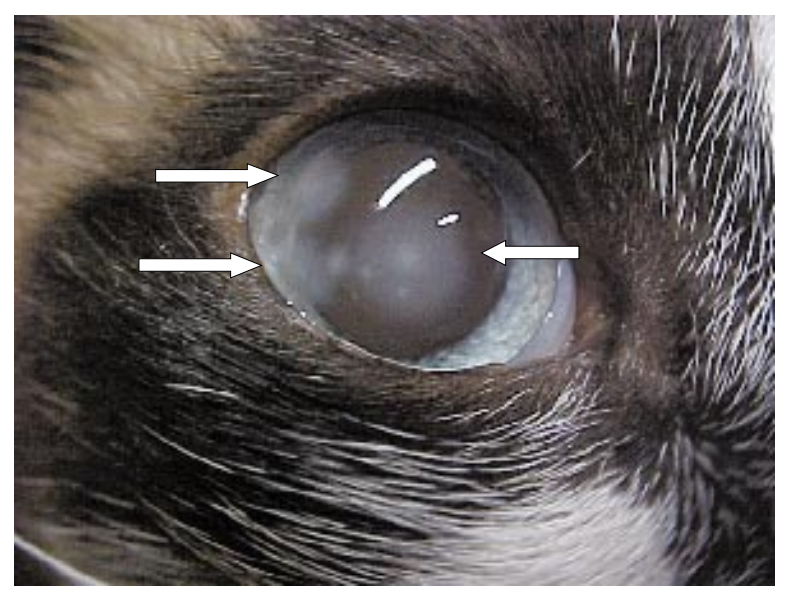

Figura 5. Felino, siamês, macho, 4 anos. Florida spot com apresentação múltipla bilateral. Detalhe do olho direito.

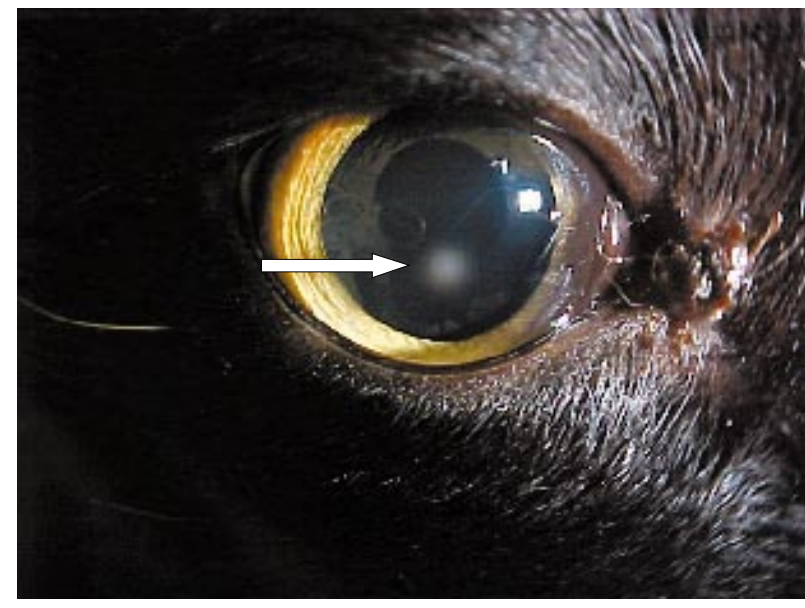

Figura 2. Felino, SRD, macho, 3 anos. Florida spot com apresentação única no olho direito (detalhe).

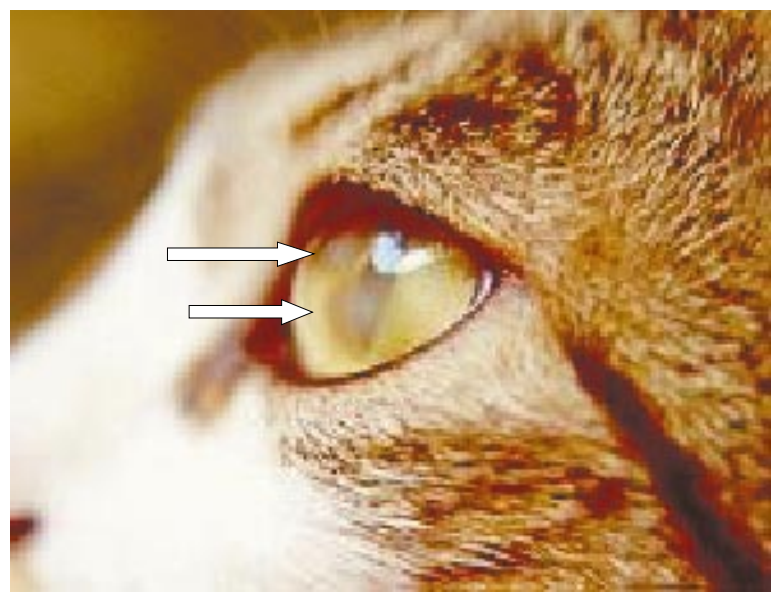

Figura 4. Felino, fêmea, SRD, 7 anos. Florida spot unilateral com apresentação múltipla no olho esquerdo.

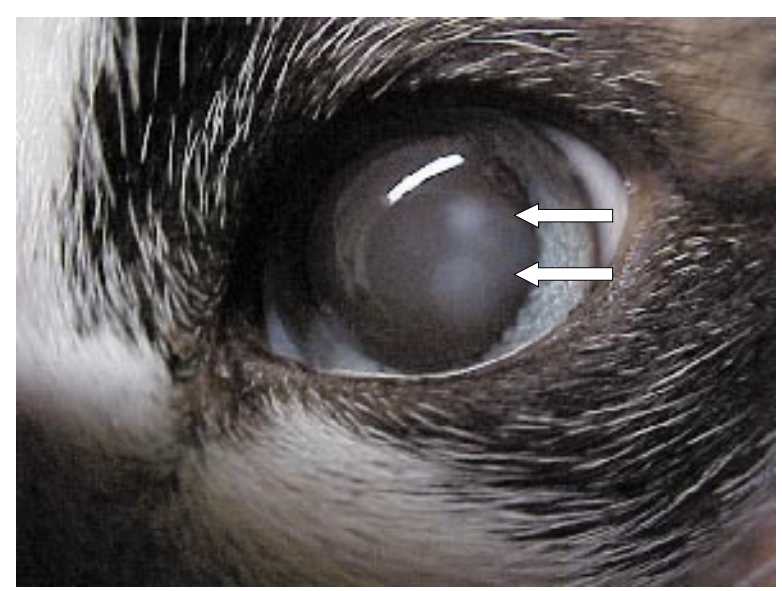

Figura 6. Felino, siamês, macho, 4 anos. Florida spot com apresentação múltipla bilateral. Detalhe do olho esquerdo. 


\section{REFERÊNCIAS}

1 Barros P.S. \& Safatle A.M.V. 1997. Florida spots in dogs and cats. A clinical study in São Paulo - Brazil. Brazilian Journal of Veterinary Research and Animal Science. 34: 276-277.

2 Nasisse M.P. 1991. Feline Ophtalmology. In: Gellat, K.N. (Ed). Veterinary Ophthalmology. Philadelphia: Lea \& Febiger, p. 545 .

3 Tucker G.S., Karpinski L. \& Fuseler J.V. 1979. Morphology and distribuition of light-scattering granules in the corneas of South Florida cats. Journal of Cell Biology. 83: 479 A.

4 Whitley R.D., Whitley E. \& McLaughlin S.A. 1993. Diagnosing and treating disorders of the feline conjunctiva and cornea. Veterinary Medicine. 88: 1138-1148. 